\title{
Structural Equation Model of Leader-Member Exchange and Organisational Citizenship Behaviour among Nurses in Malaysia
}

\author{
Junaidah Yusof, Hashim Fauzy Yaacob, Siti Aisyah Abdul Rahman, Ang Kean Hua, Noor \\ Hafizah Abdul Halim, Noor Eleena Nordin
}

\begin{abstract}
Despite the great attention received by organisational citizenship behaviour in the organisational discussion, little is known about organisational citizenship behaviour among Malaysia public hospital nurses. Hence, this study extended the discussion by investigating nurses' organisational citizenship behaviour dimensions namely altruism, courtesy, civic virtue, conscientiousness, and sportsmanship. While, the leader-member exchange consisted of perceived contribution and affect were examined as predictors of the study. Questionnaire of quantitative approach based on multi-stage cluster sampling techniques is used to obtained data from 539 nurses in Malaysia. By adopting structural equation model, the result indicates that leader-member exchange of affect dimension having a connection with altruism, courtesy, civic virtue, and sportsmanship; but vice-versa in perceived contribution dimension which only associated with sportsmanship. Theoretically, this study extends the Social Exchange Theory and its application to nursing practitioners. The findings could benefit the human resource practitioners in terms of the effects of the conduct of organisational citizenship by the nurses due to the leader-member exchange in the hospital. The study recommends the expansion of Social Exchange Theory model in organisational citizenship behaviour research by using longitudinal designs and multiple measures of other variables.
\end{abstract}

Index Terms: Structural Equation Model; Leader-Member Exchange; Organisational Citizenship Behaviour; Quantitative Approach; Multi-Stage Cluster Sampling; Nurses

\section{INTRODUCTION}

Malaysia is a rapidly developing country in which every organisation requires a powerful and effective workforce to retain its competitive advantage. The initiating major transformation of Wawasan 2020 has forced Malaysians to be more progressive in the aspects of economy, social, and intelligence in order to achieve the status of an industrialised

Revised Manuscript Received on September 22, 2019

Junaidah Yusof, Department of Psychology, Faculty of Social Sciences, Quest International University, 30250 Ipoh Perak, Malaysia, junaidah.yusof@qiup.edu.my

Hashim Fauzy Yaacob, School of Human Resource Development and Psychology, Faculty of Social Sciences and Humanities, Universiti Teknologi Malaysia, 81310 Johor Bahru, Malaysia

Siti Aisyah Abdul Rahman, School of Human Resource Development and Psychology, Faculty of Social Sciences and Humanities, Universiti Teknologi Malaysia, 81310 Johor Bahru, Malaysia

Ang Kean Hua, School of Environmental Technology, Faculty of Science and Technology, Quest International University, 30250 Ipoh Perak, Malaysia

Noor Hafizah Abdul Halim, Centre of Foundation Study, Faculty of Science and Technology, Quest International University, 30250 Ipoh Perak, Malaysia

Noor Eleena Nordin, Modern Languages Department, Faculty of Social Sciences, Quest International University, 30250 Ipoh Perak, Malaysia and developed country (1). The stressful and hectic lifestyle has caused an increasing number of Malaysians to be infected by serious illness and admitted to the hospital $(2,3)$. A recent report of Health Indicators by Ministry of Health Malaysia showed an intensified number of patient admissions in public hospitals from 2,110,628 in the year 2014 to 2,407,122 in the year 2015 , and recently $2,465,727$ in the year 2016 (4-6). Because of the increasing number of patients admitted to the hospitals, the nature of work among nurses in public sector becomes increasingly demanding and they have to face excessive workload.

Furthermore, due to the nurses' workload and their close interactions with the patients, the nurses' behaviour could be directly observed by patients and citizens (7). In recent years, the Public Complaint Bureau has received an increasing number of complaints by citizens regarding public servants behaviour in the workplace. The Public Complaint Bureau's annual reports showed in 2015, 6388 complaints have been recorded and in 2016, it increased to 6494 complaints (8). As a means to improve the service quality and service delivery, human resource practices need to be revised as the ability to respond effectively to citizen complaints lies in the willingness of the employees to exhibit citizenship behaviour. OCB is a possible solution in meeting patients' satisfaction and reducing the workload among nurses as OCB prevents nurses from being individualistic (7). It is regarded as one of the most substantial variables affecting organisational efficiency at a comparatively low price and not driven by formal reward (9). Hence, OCB would be helpful for the nurses to go beyond the call of duty to contribute to the hospital.

In ensuring that nurses, who represent a large number of population in hospital are able to consistently deliver quality service, it always depends on the leaders' capability to persuade their subordinates in an effort to meet the expectation of the patients and organisation (10-13). Hence, high-quality connections between leaders and subordinates are vital amounting to the subordinates' effectiveness and readiness in performing OCB which depends on the quality of dyadic relationships established. As suggested by Megheirkouni (11), the main idea of a dyadic relationship is focused on the relationship quality between leader and subordinates, and the positive relationship is concerning beneficial results for leaders, subordinates, groups, and the organisation. This study attempts to reveal how

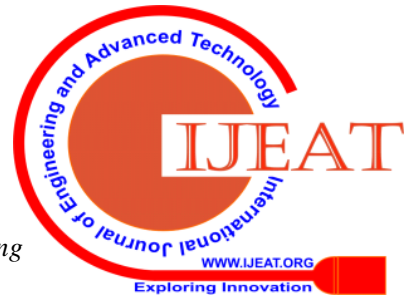


leader-member exchange (LMX) can enhance nurses' OCB in Malaysia public hospital.

Based on the Social Exchange Theory, it can be assumed nurses will exhibit OCB when they have high-quality LMX in order to maintain their positive relations with the leader. Although extensive past studies of LMX have been carried out regarding OCB $(12,13)$, most of the past research concentrated mainly on the work relations rather than both the work and interpersonal relations $(14,15)$. Therefore, this study is carried out to specifically focus on the two-dimensionalities of LMX which are perceived contribution and affect. Perceived contribution is targeted on the connection among leader and subordinate primarily based on work, while affect dimension is centred on the personal connection between leader and subordinate $(14,15)$. Hence, this study fills in the gap by confirming the distinctive nature of both dimensions by conducting a study which investigates the LMX in two different perspectives, which are the effect work relations and personal relations between leader and nurses towards five-dimensionalities of OCB rather than just focus on the work relations of LMX.

\section{LITERATURE REVIEW}

\section{A. Social Exchange Theory}

The valuable impacts can be stimulated by the social exchange relationships that are developed when employers look after the employees in the workplace setting (16). Beneficial and fair transactions amongst powerful relationship can lead to efficient work behaviour (17). Prior to the work of Blau (17), the Social Exchange Theory is the interconnection between two parties that can be acquired when one party performs a favour for the other and the other returns that favour at an appropriate time. Social Exchange Theory proposed the discretionary behaviour is connected to the subordinates determination to reciprocate to their colleagues, leaders or organisations (17). This would be for the benefits offered to the subordinates by the leader. Blau (17) revealed the subordinate involve in OCB because it extends the reciprocity, in which ways could potentially facilitate the leaders and organisations well-being.

\section{B. Organisational Citizenship Behaviour}

As a theoretical definition, Organ (9) has reported OCB as an extra-role individual behaviour which unrestricted, not directly acknowledged by the reward system, but it can encourage the organisation to function effectively. OCB also defined as the point when an individual shifts out of the frame of their own set of working responsibilities and works in a pro-social way $(18,19)$. Additionally, Organ and Ryan (20) have defined OCB as the individual contributions in the workplace that go extra-role prerequisites as specified in the job arrangement. Lastly, Bolon (21) has defined OCB as a voluntary behaviour that is displayed by employees where there is no written rule of their particular choice that they rely on, and no clear indication in the organisation's agreement. In organisational perspective, OCB has been classified into five dimensions which are altruism, courtesy, civic virtue, conscientiousness, and sportsmanship (22).

Altruism. The term altruism is used by Organ (22) to refer as helping or helpfulness. It is a behaviour where one expresses the willingness to help colleagues performing their work by aiding others by means of organisation associated task and complications (23). Some examples include offering assistance to new recruits, shouldering the work of others who are away, and helping those with high capacity of work or those who encounter work-related issues (24-26).

Courtesy. Courtesy is defined by Organ (27) as the optimistic behaviours demonstrated by the employees who is required to be in contact with the organisation and are influenced by the works and decisions of one another. Courtesy comprises actions that demonstrate special attention to establish relationships characterised by kindness and cooperation to prevent interpersonal problems from occurring (22). It involves future associated behaviours namely notifying other people before initiating action, avoiding arguments, and alarming colleagues about dangerous activities in the hospital such as construction $(25,26,28)$.

Civic Virtue. Civic virtue is, for Podsakoff et al. (29), the lively involvement of employees in the organisation's political life. This behaviour includes supporting the development of the organisation. Someone with civic virtue shows a strong sense of responsibility toward the organisation and view themselves as embodied to the organisation (29). To illustrate, it takes into account those behaviours including attending the intra-organisational meetings and discussions frequently, transforms accordingly in the organisation, problem-solving contributor, and abiding by the decisions made within the organisation $(22,29)$.

Conscientiousness. MacKenzie et al. (28) use the term conscientiousness to refer to the inclination of employees in exhibiting behaviours surpassing their least anticipated role behaviour. These behaviours indicate that special attention is given in bearing out one's task (31). To illustrate, among these are attempting to arrive on time at the workplace regardless of poor weather situations, not taking extra breaks, and working past normal office hours $(21,27,32)$.

Sportsmanship. In simple words, sportsmanship is known as a tolerance among employees in the workplace. Tolerance is the evasion of negative behaviour that might trigger conflict among colleagues (21). Tolerate in terms of the readiness in encountering difficulties and work impositions devoid of any objection (27). Employees with good sportsmanship will confront the challenges in the workplace and prevent any unduly complains, being positive, and experienced workplace problems by enduring them (31). Examples of sportsmanship behaviours include avoiding the pointless conversation, not wasting time by talking about work problems, and evading discourteous behaviours against colleagues $(21,25,26)$.

\section{Leader-Member Exchange}

The theoretical definition of LMX is the relationship quality that is developed among the leader and the subordinate on the basis of the pair's reciprocal affection towards one another based mainly on interpersonal appeal instead of work values (33). LMX is defined by Bhal and Ansari $(14,15)$ as the exchange relationship trait amongst the leader and the subordinate in the workplace in which that 
relationship depends on perceived contribution and affect.

Perceived contribution. According to Dienesch and Liden (35), it is clarified as the perception of work-oriented activity concerning the quantity, direction, and quality that every subordinate proposes toward the pair's reciprocal goals. Responsibility, efficiency, and amount of effort taken by the leader and the subordinate have been measured in perceived contribution (14). Bhal and Ansari (14) described that this dimension was considered the greatest power factor of both the leader and subordinate viewpoints.

Affect. Specified as a gentle feeling of liking between the subordinates and the leader which substantially focused on interpersonal appeal instead of work values (35). Specifically, affect refers to the interpersonal fondness concerning the leader and the subordinate besides work-related features of the pair (14). Affect is also measured by non-work related communication and assisting more towards personal perspectives (14).

\section{LMX on OCB}

LMX plays an important role to forecast OCB because employees with high-quality LMX will enjoy an exceptional and beneficial connection with their leaders $(36,37)$. Form this relation, employees will engage in OCB by being part of the competency and productiveness of the organisation due to the feeling of indebted in returning the benefits. Podsakoff et al. (30) and Organ et al. (25) have stated that exchanges of resources that go over those specified in the formal requirements are considered as high-quality relationships. Hence, the high possibility of employees getting engage in OCB. Low-quality LMX, on the other hand, identifies less favourably with leaders and perceived leader behaviours, thus making subordinates less likely to reciprocate effort that benefits others (38).

There are also a considerable amount of studies which have found evidence on the influence of LMX on OCB. A notable example of this is a study by Wang et al. (36) among 214 employees in China has reported LMX gives a positive effect to OCB. Additionally, the research data gathered from 245 employees analysed by Anand et al. (39) also reported that LMX is associated with OCB. In the Malaysia context, Rashidah et al. (13) have conducted research on the perception of local governments' employees of LMX towards OCB. The research shown a good relationship between the leader and the subordinates enhance subordinates' OCB. All these researchers used the Social Exchange Theory by Blau (17) as a fundamental research theory to prove that the subordinates will demonstrate more OCB in order to fulfil reciprocity obligations when the LMX is high. Consequently, OCB would increase among employees if the quality of LMX is high (40). From the previous studies mentioned above, it is clear that LMX influences OCB among employees.

\section{METHODOLOGY/MATERIALS}

\section{A. Materials}

In order to give a clear orientation in achieving research objectives validly and economically, it is vital for research has a proper outline of research design especially in social sciences discipline (41). A quantitative research strategy was chosen to resolve the research questions given that it is a non-experimental study. The participants who are the nurses U29 in Malaysia public hospitals were given a self-reported survey which is then synthesized as the data for this study. Hence to gather the information required, multi-stage cluster sampling was used in this study. Multi-stage cluster sampling is used when the research involves a wide area and large population size which makes it difficult or impossible to list the subjects. The larger clusters are further subdivided into smaller sub-clusters or groups (42).

\section{B. Organisational Citizenship Behaviour}

In this study, the researcher adapted the Organisational Citizenship Behaviour Scale by Podsakoff et al. (29) to measure OCB. The instrument consists of 24 items that represent the five dimensions of OCB which are altruism (5 items), courtesy (5 items), civic virtue (4 items), conscientiousness (5 items), and sportsmanship (5 reverse items). This is one of a dependable instrument among prior instruments in the field of OCB because it has high and good internal consistency. Examples of items are 'I help orient new staff nurses even though it is not required' (altruism), 'I take steps to try to prevent problems with another staff nurse' (courtesy), 'I read my hospital announcements and memos' (civic virtue), 'I obey hospital rules and regulations even when no one is watching' (conscientiousness), and 'I consume a lot of time complaining about unimportant matters' (reverse item of sportsmanship). The items were scored with 5-points on a Likert scale from 1=strongly disagree to $5=$ strongly agree.

\section{Leader-Member Exchange}

The researchers adapted the Leader-member Exchange Scale by Bhal and Ansari (14) to measure LMX. The instrument consists of 8 items with 4 items representing each of the dimensions (i.e. perceived contribution and affect). It has high and good internal consistency which is between 0.78 to 0.93 and was widely tested in various cross-cultural context including among Asian people $(14,15,43)$. Examples of items are 'My leader takes much responsibility for the jobs that are to be done together with me' (perceived contribution) and 'My leader and I often seek advice from each other on personal problems' (affect). All of the items were scored with 7-point on a Likert scale from $1=$ strongly disagree to $7=$ strongly agree.

\section{RESULTS AND FINDINGS}

\section{A. Data Collection}

Although the minimum sample size required in this study was 382 , the researchers decided to distribute 1531 sets of questionnaires so as to boost the response rate from the respondents. Unfortunately, the researchers only managed to get 539 respondents from four selected hospitals with the return rate about 35.2 percent from the four selected government hospitals in Malaysia.

\section{B. Methods of Analysis}

Prior to running hypothesis testing, a few tests on raw data of the study were run. This was

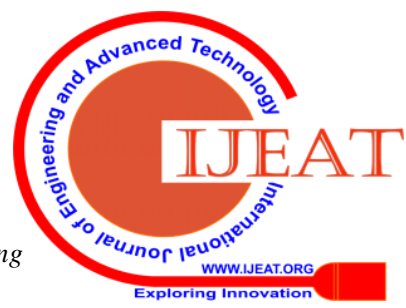


done to ensure that all the data was complete which is important in avoiding error during the data analysis stage. In this research, four tests were conducted in the data preparation stage which were missing data analysis, Mahalanobis distance test for multivariate outliers detection, normality analysis, and multicollinearity assumption of the data. Missing data analysis was executed using IBM SPSS software 23 where it identified incomplete questionnaire in this study. Mahalanobis distance test was executed using IBM SPSS Amos 23 where it detected potential multivariate outliers in the data. Normality analysis of kurtosis and skewness were executed using IBM SPSS software 23 to determine the normality distribution of the data.

Additionally, multivariate analysis was utilised with regard to answer the research objectives. Structural Equation Modelling is a statistical approach used for testing the cause and effect of the tested variable. It is used to measure the comparative strength of the indirect and direct relationship of variables. The Structural Equation Modelling was chosen to answer the research objectives because it allowed the researcher to test multiple variables simultaneously in a single model. Besides, the use of Structural Equation Modelling could reduce measurement error and thus lead to a clear and valid conclusion regarding the overall model of the study (44). A structural Equation Modelling approach was executed using IBM SPSS Amos 23 software. The final result was determined using $\mathrm{p}$-value where the $\mathrm{p}$-value below 0.05 for estimate indicated that direct effect is significantly existed. In this study, the direct effect model measures direct relationship from LMX on OCB.

\section{Result}

This study intended to assess the direct effect of LMX dimensions (i.e. perceived contribution and affect) on $\mathrm{OCB}$ dimensions (i.e. altruism, courtesy, civic virtue, conscientiousness, and sportsmanship) among Malaysia public hospital nurses. The result indicated the model for the influence of LMX dimensions on OCB dimensions has yielded a good fit with RMSEA $=0.05, \mathrm{GFI}=0.90$, AGFI $=$ $0.88, \mathrm{CFI}=0.95, \mathrm{TLI}=0.94, \mathrm{NFI}=0.90$, and chisq $/ \mathrm{df}=2.01$. Overall, the perceived contribution and affect found to explain 5.1 percent of altruism occurrence, 2.6 percent of courtesy occurrence, 5 percent of civic virtue occurrence, 1 percent of conscientiousness occurrence, and 4 percent on sportsmanship occurrence among Malaysia public hospital nurses.

Accordingly, Table 1 summarises the direct effect result for the influence of LMX dimensions on OCB dimensions. Specifically, perceived contribution was found to significantly give an effect to only sportsmanship ( $\beta=0.242$, $p<0.001)$. That is, the high quality of perceived contribution increases the occurrence of sportsmanship among nurses. However, the perceived contribution has an insignificant effect on altruism, courtesy, civic virtue, and conscientiousness.

Table 1 Direct Effect Result of LMX on OCB

\begin{tabular}{lccccccc}
\hline $\begin{array}{l}\text { Leader-me } \\
\text { mber } \\
\text { Exchange }\end{array}$ & $\begin{array}{c}\text { Pat } \\
\mathbf{h}\end{array}$ & OCB & $\mathbf{R}^{2}$ & SRW & $\begin{array}{c}\text { S. } \\
\text { C.R }\end{array}$ & $\begin{array}{c}\text { P-val } \\
\text { ue }\end{array}$ \\
\hline Perceived & $\rightarrow$ & Altruism & .05 & .100 & .04 & 1.52 & .128
\end{tabular}

\begin{tabular}{|c|c|c|c|c|c|c|c|}
\hline $\begin{array}{l}\text { Contributio } \\
n\end{array}$ & & & 1 & & 8 & 2 & \\
\hline Affect & & & & $.153 *$ & $\begin{array}{c}.05 \\
3\end{array}$ & $\begin{array}{c}2.29 \\
4\end{array}$ & .022 \\
\hline $\begin{array}{l}\text { Perceived } \\
\text { Contributio }\end{array}$ & $\rightarrow$ & Courtesy & $\begin{array}{c}.02 \\
6\end{array}$ & .079 & $\begin{array}{c}.04 \\
0\end{array}$ & $\begin{array}{c}1.30 \\
0\end{array}$ & .194 \\
\hline Affect & & & & $.102 *$ & $\begin{array}{c}.04 \\
4\end{array}$ & $\begin{array}{c}2.15 \\
6\end{array}$ & .032 \\
\hline $\begin{array}{l}\text { Perceived } \\
\text { Contributio } \\
n\end{array}$ & $\rightarrow$ & Civic Virtue & $\begin{array}{c}.05 \\
0\end{array}$ & -.007 & $\begin{array}{c}.04 \\
6\end{array}$ & $\begin{array}{c}-.13 \\
9\end{array}$ & .889 \\
\hline Affect & & & & $\begin{array}{c}.228 * \\
* *\end{array}$ & $\begin{array}{c}.05 \\
2\end{array}$ & $\begin{array}{c}3.44 \\
0\end{array}$ & $* * *$ \\
\hline $\begin{array}{l}\text { Perceived } \\
\text { Contributio } \\
\text { n }\end{array}$ & $\rightarrow$ & $\begin{array}{c}\text { Conscientio } \\
\text { usness }\end{array}$ & $\begin{array}{c}.01 \\
0\end{array}$ & .115 & $\begin{array}{c}.03 \\
9\end{array}$ & $\begin{array}{c}1.42 \\
6\end{array}$ & .154 \\
\hline Affect & & & & -.103 & $\begin{array}{c}.04 \\
3\end{array}$ & $\begin{array}{c}-1.2 \\
93\end{array}$ & .196 \\
\hline $\begin{array}{l}\text { Perceived } \\
\text { Contributio } \\
n\end{array}$ & $\rightarrow$ & $\begin{array}{c}\text { Sportsmans } \\
\text { hip }\end{array}$ & $\begin{array}{c}.04 \\
0\end{array}$ & $\begin{array}{c}.242 * \\
* *\end{array}$ & $\begin{array}{c}.04 \\
6\end{array}$ & $\begin{array}{c}3.59 \\
2\end{array}$ & $* * *$ \\
\hline Affect & & & & $\begin{array}{c}-.164 \\
* * *\end{array}$ & $\begin{array}{c}.05 \\
0\end{array}$ & $\begin{array}{c}-2.4 \\
05\end{array}$ & $* * *$ \\
\hline
\end{tabular}

$\mathrm{p}<0.001^{* * * ;} \quad \mathrm{p}<0.05^{*} ; \quad$ OCB means Organisational Citizenship Behaviour; $\mathrm{R}^{2}$ means Squared Multiple Correlation Coefficients; SRW means Standardized Regression Weight; CR means Critical Ratio

\section{DISCUSSION}

The aim of this study is to assess a comprehensive model regarding the effect of LMX on OCB. This research model involved LMX as predictor and the main variables, while OCB as the outcome variable. The significant effect of LMX on OCB is supported by the Social Exchange Theory by Blau (17). The Social Exchange Theory by Blau (17) has explained a mechanism that high-quality LMX among employees is likely to engage in OCB due to a reciprocal exchange relationship. Reciprocal exchange relationship in this theory has explained that positive behaviour such as OCB exhibited by the employee is based on the response to the treatment they received from their leader. Shim et al. (45) revealed that the productivity of public servants and government agencies could be increased by implementing the good soldier syndrome or known as OCB. Anand et al. (39) said this happens because of high-quality LMX shows high levels of interchangeable information, communication, trust, and support between the leader and the subordinates, and these interactions will increase the subordinate's willingness to perform more OCB. This result is also supported by Almasradi et al. (46) which has suggested based on the norm of reciprocity, the subordinate will return leader's favourable treatment by go in for extra behaviours even if these behaviours are not rewarded under the formal organisation reward system.

Specifically, the study revealed high quality perceived contribution increases the sportsmanship behaviour among Malaysia public hospital nurses. However, this study indicated that work-based 
relationship between leader and subordinate has no significant association to altruism, courtesy, civic virtue, and conscientiousness. A high perception of the amount, direction, and quality of work-oriented activity between the leader and the subordinate put forth toward the mutual goal can enhance the level of sportsmanship performance among subordinates $(43,47)$. According to the enactment of Social Exchange Theory by Blau (17), perceived contribution become one of the basic elements in the workplace social exchange network especially in reciprocating the leader and subordinate relationship (43). Good quality of work-based relationship is said to give an impact on employees' intrinsic motivation for being helpful and minimise the unnecessary complain (48), because when employees get guidance and explanation on the job difficulties in the workplace, they can face job difficulties without complaint. Thus, nurses who experienced high quality work-based relationship between leader and subordinate will lead to less complaining behaviour as an exchange.

Next, this study revealed that affect is remarkably associated with altruism, courtesy, and civic virtue but not significantly towards conscientiousness. Affect is based on attraction or fondness to one another that is premised on the personal relationship between the leader and the subordinate. It means that a good quality personal-based relationship between the leader and the subordinate can increase the occurrence of altruism, courtesy, and civic virtue among Malaysia public hospital nurses. The presence of a high-quality personal-based relationship between the leader and the subordinate indicates that the leaders have good control over their own subordinates in personal matters (43). Dulebohn et al. (40) have indicated that a high-quality personal-based relationship between the leader and the subordinate can increase the occurrence of being helpful, good interpersonal behaviour, and high involvement of organisational activities among employees. Therefore, the result of this study revealed that high quality personal-based relationships between the leaders and the subordinates give nurses more opportunity to perform altruism, courtesy, and civic virtue in hospital.

Based on previous studies $(13,47)$, a good quality personal-based relationship between the leader and the subordinate supposedly gives a positive effect on sportsmanship, but the result of this study indicated that good quality personal-based relationship between the leader and the subordinate gives a negative effect to sportsmanship. That is, a high-quality personal-based relationship can decrease the nurses' sportsmanship behaviour. A plausible reason for this result is perhaps, a good personal relationship between the leader and the subordinate causes the subordinates to feel more welcomed to make a complaint even for unnecessary things rather than being positive and tolerant towards the problems experienced at the workplace. Bowler et al. (50) have pointed out that when the employees are too familiar with their leader, the subordinates may take personal advantage in the workplace as a return of this relationship. Moreover, at a certain point, a too close personal relationship between the leader and the subordinates at work can cause the subordinates to feel that there is no boundary between them and their leader. This condition stimulates the subordinate to cultivate the feeling of friendship instead of respectfulness to the leader. Perhaps, a high-quality personal-based relationship between the leader and the subordinate is perceived as difficult and troublesome, thus making it impractical to enrich nurse's sportsmanship at the workplace. Therefore, too close personal-based relationship between the leader and the subordinate among nurses should be controlled and used in a positive way to reduce the possibility of being taken advantage of manipulated from this relationship thus lowering the sportsmanship behaviour.

As a summary, it is concluded that the work-based relationship between the leader and the subordinate increases the behaviour of sportsmanship in a positive direction among Malaysia public hospital nurses. Overall, this study has revealed that high-quality personal-based relationship between the leader and the subordinate can be beneficial in increasing nurses' behaviour of altruism, courtesy, and civic virtue. However, the results indicated that high-quality personal-based relationship between the leader and the subordinate can decrease nurses' sportsmanship behaviour in the workplace. It is suggested that a good personal relationship between the leader and the subordinate does not always give a positive impact but it can also bring negative side effects. The results provided a new perspective on affect dimension where it does not necessarily bring a positive effect to the nurses but may also lead to a negative effect on sportsmanship behaviour. Additional studies need to be conducted in order to develop more understanding of the effect of the personal-based relationship between the leader and the subordinate on sportsmanship behaviour. Furthermore, as a leader, they should know how to balance between work and personal relationship with their subordinates in order to increase the performance of the employee's OCB in the organization.

\section{CONCLUSION}

This study contributes to current theoretical development and application implementation in several ways. In term of theoretical development, the framework of this study was grounded by the structure of Social Exchange Theory where this study expanded from the original structure of Social Exchange Theory within the context of LMX and OCB. Figure 2 illustrates the final model of the study. While, in term of implications, the results of this study provide valuable information on the importance of OCB among nurses in the workplace. The information gained from this research might help hospitals and Malaysia Ministry of Health to design a better working environment that emphasis on OCB at work. A positive work environment is important in order to increase work performance among them. In addition, the information from this study is also beneficial in assisting Malaysia Ministry of Health in designing specific interventions or training programs that emphasis on performing OCB at work. 


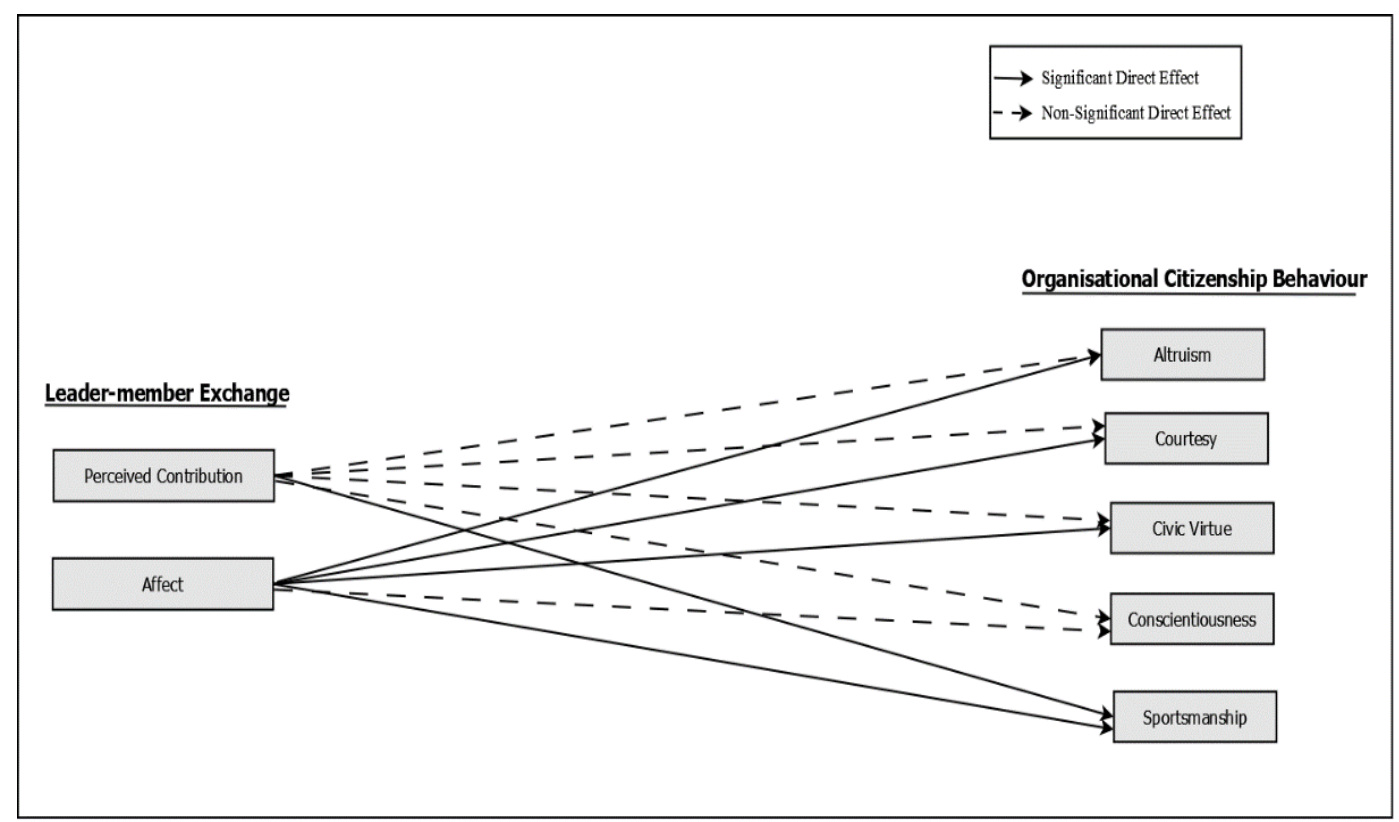

Fig 2 Final model of the study

Thus far, from this study, there were also limitations and suggestions for future consideration. First, this study is focused on investigating the hospital setting specifically among Malaysia public hospital nurses. Therefore, the research findings cannot be generalised to the nurses in a private hospital or other different groups in other organisations. Since the findings might be different based on the nature of the population, future researchers may replicate and extend the current model of the study into a different population. In addition, this research utilised a cross-sectional research design. This design only allowed the researcher to gather the data within a particular time. This design has a disadvantage which is it has limited capability to establish strong findings and conclusion since it cannot measure the causal effect of the model over time (51). A longitudinal design study should therefore be carried out in the future, since this design is capable of drawing causal conclusions among the variables and gives a clearer explanation on antecedents of nurses' OCB that explained over time.

\section{ACKNOWLEDGEMENTS}

We are grateful for the opportunity provided by Quest International University and Universiti Teknologi Malaysia to publish our research finding.

\section{REFERENCES}

[1] Jabatan Perkhidmatan Awam. TN50: Aspirasi Malaysia. TN50: Transformasi Nasional 2050. 2017. p. 1-14.

[2] 2. Anvari R, Barzaki AS, Amiri L, Irum S, Shapourabadi S. The mediating effect of organizational citizenship behavior on the relationship between workplace spirituality and intention to leave. Intang Cap. 2017;13(3):615-39.

[3] 3. Sang Long C, Owee Kowang T, Ai Ping T, Muthuveloo R. Investigation on the impact of job stressors on nurses in Malaysia. Asian Soc Sci. 2014;10(4):67-77.

[4] 4. Ministry of Health Malaysia. Health Indicatiors 2016: Indicators for monitoring and evaluation for strategy health for all. 2017.

[5] 5. Ministry of Health Malaysia. Health Indicators 2015: Indicators for Monitoring and Evaluation of Strategy Health for All. 2016.

[6] 6. Ministry of Health Malaysia. Health Indicators 2014: Indicators for Monitoring and Evaluation of Strategy Health for All. 2015.
[7] 7. Yu HY, Lou JH, Eng CJ, Yang CI, Lee LH. Organizational citizenship behaviour of men in nursing professions: Career stage perspectives. Collegian. 2018;25:19-26.

[8] 8. Public Complaints Bureau Prime Minister's Department. Complaint Statistics of Annual Reports 2015 and 2016. In: SISPAA System. 2018. p. 1-13.

[9] 9. Organ DW. Organizational Citizenship Behavior: The good Soldier Syndrome. DC: Lexington; 1988.

[10] 10. Ismail A. Leadership in the Malaysian Public Service. J Public Serv. 2007;6(1):1-22.

[11] 11. Megheirkouni M. Revising leader-member exchange theory: Insights into stadia management. Int $\mathrm{J}$ Event Festiv Manag. 2017;8(3):244-60

[12] 12. Newman A, Schwarz G, Cooper B, Sendjaya S. How servant leadership influences organizational citizenship behavior: The roles of LMX, empowerment, and proactive personality. J Bus Ethics. 2017;145:49-62.

[13] 13. Rashidah MI, Aziz A, Munir S. The role of leader-member exchange in elevating local government employees' OCB: An empirical evidence from East Coast Malaysia. Int J Bus Soc Sci. 2014;5(6):161-70.

[14] 14. Bhal KT, Ansari MA. Measuring quality of interaction between leaders and members. J Appl Psychol. 1996;26(11):945-72.

[15] 15. Bhal KT, Ansari MA. Managing dyadic interaction in organizational leadership. New Delhi: Sage; 2000.

[16] 16. Cropanzano R, Byrne ZS, Bobocel DR, Rupp DE. Moral Virtues, Fairness Heuristics, Social Entities, and Other Denizens of Organizational Justice. J Vocat Behav. 2001;58:164-209.

[17] 17. Blau PM. Exchange and Power in Social Life. New York: Jossey-Bass; 1964.

[18] 18. Karriker JH, Williams ML. Organizational justice and organizational citizenship behavior: A mediated multifoci model. J Manage. 2009;35(1):112-35.

[19] 19. Puffer S. Prosocial behavior, noncompliant behavior, and work performance among commission salespeople. J Appl Psychol. 1987;36(4):53-60.

[20] 20. Organ DW, Ryan K. A Meta-analytic review of attitudinal and dispositional predictors of organizational citizenship behavior. Pers Psychol. 1995;48(4):775-802.

[21] 21. Bolon DS. Organizational Citizenship Behavior among Hospital Employees: A Multidimensional Analysis Involving Job Satisfaction and Organizational Commitment. Hosp Heal Serv Adm. 1997;42(2):221-41.

[22] 22. Organ DW. Organizational citizenship behavior: It's construct cleanup time. Hum Perform. 1997;10(2):85-97.

[23] 23. Smith A, Organ DW, Near PJ. Organizational Citizenship Behavior: Its Nature and Antecedents. J Appl Psycchology. 1983;68(4):653-63. 
[24] 24. Jahangir N, Muzahid Akbar M, Haq M. Organizational Citizenship Behavior: It is Nature and Antecedents. Brac Univ J. 2004;1(2):75-85.

[25] 25. Organ DW, Podsakoff PM, MacKenzie SB. Organizational Citizenship Behavior: Its Nature, Antecedents, and Consequences. New Delhi: Sage Publications Inc; 2006.

[26] 26. Schnake ME, Dumbler MP. Levels of measurement and analysis issues in organizational citizenship behavior research. J Occup Organ Psychol. 2003;76:283-301.

[27] 27. Organ DW. The Motivational Basis of Organizational Citizenship Behavior. Res Organ Behav. 1990;12:43-72.

[28] 28. MacKenzie SB, Podsakoff, P. M., Fetter R. The impact of organizational citizenship behaviour on evaluations of sales performance. J Mark. 1993;57:70-80.

[29] 29. Podsakoff NP, MacKenzie SB, Moorman RH. Transformational Leader Behaviors and Their Effects on Followers' Trust in Leader, Satisfaction and Organizational Citizenship Behaviors. Leadersh Q. 1990;1:107-42.

[30] 30. Podsakoff P, MacKenzie S, Paine J, Bachrach D. Organizational Citizenship Behavior: A Critical Review of the Theoretical and Empirical Literature and SUggestions for Future Research. J Manage. 2000;26(3):513-63.

[31] 31. Podsakoff PM, MacKenzie SB. Organizational citizenship behaviors and sales unit effectiveness. J Mark Res. 1994;31:351-63.

[32] 32. MacKenzie SB, Podsakoff, P. M., Fetter R. Organizational citizenship behavior and objective productivity as determinants of managerial evaluations of salespersons' performance. Organ Behav Hum Decis Process. 1991;50(1):123-50.

[33] 33. Sparrowe RT, Liden RC. Process and structure in leader-member exchange. Acad Manag Rev. 1997;22(2):522-52.

[34] 34. Graen GB, Novak MA, Sommerkamp P. The effects of leader-member exchange and job design on productivity and satisfaction: Testing a dual attachment model. Organ Behav Hum Perform. 1982;30:109-31.

[35] 35. Dienesch RM, Liden RC. Leader-member exchange model of leadership: A critique and further development. Acad Manag Rev. 1986;11:618-34.

[36] 36. Michel JW, Tews MJ. Does leader-member exchange accentuate the relationship between leader behaviors and organizational citizenship behaviors? J Leadersh Organ Stud. 2016;23(1):13-26.

[37] 37. Sun LY, Siu Chow IH, Chiu RK, Pan W. Outcome favorability in the link between leader-member exchange and organizational citizenship behavior: Procedural fairness climate matters. Leadersh Q. $2013 ; 24: 215-26$

[38] 38. Zhong JA, Lam W, Chen Z. Relationship between leader-member exchange and organizational citizenship behaviors: Examining the moderating role of empowerment. Asia Pacisic J Manag. 2011;28:609-26.

[39] 39. Anand S, Vidyarthi P, Rolnicki S. Leader-member exchange and organizational citizenship behaviors: Contextual effects of leader power distance and group task interdependence. Leadersh Q. $2017 ; 1-12$

[40] 40. Dulebohn JH, Wu D, Liao C. Does liking explain variance above and beyond LMX? A meta-analysis. Hum Resour Manag Rev. 2017;27(1):149-66.

[41] 41. Creswell JW. Research Design: Qualitative, Quantitative and Mixed Method Approaches. California: Sage Publications Inc; 2003.

[42] 42. Piaw CY. Mastering Research Methods. Kuala Lumpur: McGraw Hill; 2012.

[43] 43. Bhal KT, Ansari MA. Leader-member exchange-subordinate outcomes relationship: Role of voice and justice. Leadersh Organ Dev J. 2007;28(1):20-34

[44] 44. Awang Z. Structural Equation Modeling using Amos Graphic. UITM Press; 2012

[45] 45. Shim DC, Park HH, Jeong SY. Government employees' organizational citizenship behavior amid organizational resource decline: Can they work more with less. Rev Public Pers Adm. $2017 ; 1-23$.

[46] 46. Almasradi RB, Siti Aisyah P, Chikaji AI. The relationship between LMX and OCB in Saudi Arabia: Review of Literature. Adv Sci Lett. 2017;23(9):8843-5.

[47] 47. Han Y, Sears G, Zhang H. Revisiting the "give and take" in LMX: Exploring equity sensitivity as a moderator of the influence of LMX on affiliative and change-oriented OCB. Pers Rev. 2018:47(2):555-71.
[48] 48. Tambe S, Shanker M. A Study of Organizational Citizenship Behaviour (OCB) and Its Dimensions : A Literature Review. Int J Bus Manag. 2014;1:67-73.

[49] 49. Banwo AO, Du J. When the good outweight the bad: Organizational citizenship behaviour (OCB) in the workplace. Hum Resour Dev Int. 2018;1-10.

[50] 50. Bowler W, Paul J, Halbesleben J. LMX and attributions of organizational citizenship behavior motBives: When is citizenship perceived as brownnosing. J of Business and Psychology. 2017;1-14

[51] Sekaran U. Research methods for business. Hoboken: NJ John Wiley \& Sons; 2003

\section{AUTHOR'S PROFILE}

Junaidah Yusof, Affilated with Department of Psychology, Faculty of Social Sciences, Quest International University, Malaysia,

Hashim Fauzy Yaacob, Affiliated with chool of Human Resource Development and Psychology, Faculty of Social Sciences and Humanities, Universiti Teknologi Malaysia,

Siti Aisyah Abdul Rahman, Associate Professor School of Human Resource Development and Psychology, Faculty of Social Sciences an Humanities, Universiti Teknologi Malaysia, The Research interests includes Worklife balance, Occupational Well-being and Corportae Integrity

Ang Kean Hua, School of Environmental Technology, Faculty of Science and Technology, Quest International University, Malaysia.

Noor Hafizah Abdul Halim, Centre of Foundation Study, Faculty of Science and Technology, Quest International University, Malaysia

Noor Eleena Nordin, Modern Languages Department, Faculty of Social Sciences, Quest International University, 30250 Ipoh Perak, Malaysia 